\title{
FOOD WASTAGE: A CONCERN ACROSS THE SOUTH AFRICAN QUICK SERVICE RESTAURANT SUPPLY CHAIN
}

\author{
NADENE MARX-PIENAAR, GERRIE DU RAND, ANNEMARIE VILJOEN \& HENNIE FISHER \\ Department of Consumer and Food Sciences, University of Pretoria, South Africa
}

\begin{abstract}
Global estimates suggest that between one third to half of all food produced never reach the human stomach. Recent figures estimate South African (SA) food waste at R61.5 billion per annum (current exchange rate R12.23 =\$1). With the Food and Agriculture Organisation's (FAO) reports underscoring the food insecurity of many SA households, addressing food wastage in SA has become a matter of great significance. Unfortunately, information pertaining to food waste in SA tends to be limited. Not only is information detailing the proportion of waste at key supply chain areas needed, identifying critical areas of concern with possible mitigating strategies is also warranted. This study aimed at alleviating the knowledge deficit regarding food waste by investigating current food product practices throughout a SA quick service restaurant (QSR) supply chain. Data collection entailed two phases. Phase one involved a supply chain audit that documented practices and managerial protocols which could contribute towards unnecessary wastage. Phase two involved interviewing QSR managers, which allowed identifying possible mitigating strategies. Results revealed that production, distribution and packaging in particular secondary packaging warrants attention. However, in terms of human resources, findings also accentuated consumers', managers', and employees' general awareness of food waste as worrisome.
\end{abstract}

Keywords: food waste, quick service restaurant (QSR), supply chain.

\section{INTRODUCTION}

Municipal waste composition studies globally have indicated that vast amounts of food are wasted and disposed while there is potentially significant opportunity to prevent food wastage at various levels throughout the supply chain [1], [2]. International trends suggest that food wastage moves up the food supply chain, from pre-consumer to post-consumer stages, as the level of development in a country increases [3]. It is therefore likely that South Africa (SA), as an emerging economy, may see similar trends in food waste over time. To date little information is available to present the issue of food waste from a SA perspective. Not only is information detailing the proportion of waste contributed by each key area in the supply chain needed, but identifying critical areas of concern and recommending possible mitigation strategies, is also an urgent matter. Global estimates suggest that between one third to half of all food produced never reach the human stomach [4]. With Food and Agriculture Organisation (FAO) [5], [6] reports highlighting the fact that many SA households are indeed food insecure, SA can no longer avoid the urgent call to address the matter of unnecessary food wastage. This being said, planning and or formulating mitigation strategies based on the currently available information is viewed as irresponsible, as this information is often not only limited but also unreliable. Nevertheless, mitigation of food waste is greatly needed in order to ensure the welfare of SA's natural, economic and social environment.

The aim of this study was therefore firstly to attempt to alleviate the knowledge deficit regarding food waste by not only investigating current food product management and practices throughout a SA quick service restaurant (QSR) supply chain, but to also identify areas of concern that contribute towards unnecessary food wastage. Secondly, the study 
envisaged to suggest possible supply chain solutions that could be implemented to mitigate the issue at hand.

\section{THE ROLE OF THE FOOD SUPPLY CHAIN}

Today's consumers live in a world with convenient access to an abundance of fast food outlets also known as QSR, all designed to meet their ever-increasing needs and demands [7]. The food supply chain is a key player in ensuring that retail and food service outlets are able to meet the demands set by consumers [8], [9]. Defined as a series of interdependent links along which food travels along from farm to fork, the food supply chain ensures food is delivered in a seamless and timely manner, at a price and in a place perfectly suited to the consumer [10]. The food supply chain is managed by a wide range of disciplines with a wide range of skills, governed by a framework of quality standards and rules. Effective supply chain management in the food industry is a valuable commodity as it leads to both cost reduction and enhanced service. However, ineffective supply chain management can consequently lead to a host of problems - one of these problems being food waste [10].

\section{THE QUICK SERVICE RESTAURANT INDUSTRY (QSR)}

A Quick Service Restaurant (QSR) is defined as a type of restaurant in which cooking is done in a fast and time-conscious manner, and is also identified by its insignificant table service because food is mostly consumed off-site i.e. "take away" [11]. In SA the QSR sector, or fast food industry, is currently experiencing massive growth. Recent studies noted a significant increase in patronage among SA consumers, from at least once every four weeks in 2009 to at least once every week in 2015 [11], [12]. This growth in QSRs simultaneously comes with a growth of supply chains that need to keep them functioning at optimal levels. Often, QSRs form part of a large chain of stores and when a chain becomes too big, the quality of management and efficiency of respective QSRs is compromised, causing food wastage to rise. Contributing to this growth in SA is a growing black middle class and the establishment of QSRs in rural and previously disadvantaged areas [12]. It should be noted that the exponential growth in this industry tends to be an unwavering phenomenon and that not even rising commodity prices, recent food safety and hygiene threats, or market saturation have had a dampening effect. However, this growth is accompanied by a number of concerns, one of which is food waste, a concept which has not been extensively researched and defined in SA [4], but is a definite problem as SA's developing economy transforms into an emerging economy.

\section{FOOD WASTE}

Food waste has become a global issue, with approximately $50 \%$ of all food which is produced for human consumption being wasted along the food supply chain [9], [13]. Food waste across the food supply chain in SA alone is estimated at 10.2 million tons per annum, at a cost of approximately R61.5 billion per annum (current exchange rate R12.23 $=\$ 1$ ) [14]. It is estimated that post-consumer food waste represents a marginal proportion when considering the total amount of food wastage in SA, with the majority of food waste likely to be found at pre-consumer stages [3].

Reviewing literature on food waste poses a scenario where one is often confronted with a myriad of definitions, and little consensus. This being said, the following three principal definitions seem to be the most prominent.

1.) The FAO defines food waste as any material intended for human consumption, at any point in the food supply chain that is discarded, lost, degraded or consumed by pests [5]. 
2.) Derqui et al. [15] explains that food waste should be viewed as the intentional discarding of food items that still have nutritional value and is thus still fit for human consumption.

The premise behind these first definitions echoes the reasoning behind the classification presented by WRAP (Waste Resources and Action Programme) [16] which states that food waste could be divided into two categories, namely avoidable and unavoidable waste. Avoidable waste is the wasting of food products or parts of products that are considered safe to consume by people, whereas unavoidable waste refers to the disposal of food products that are unacceptable for consumption under normal conditions.

3.) In addition to the previous definitions, food waste is also defined as the difference between the energy value of consumed food per capita and the energy value of food needed per capita, i.e. over-nutrition [17]. Based on the different definitions and consequential interpretation of "food waste" as a concept, it is apparent that addressing the problem poses significant challenges. Failure to address food waste will be to the detriment of our social, natural and economic environment.

Three major concerns are associated with food waste. The first is global food security, in which large quantities of discarded food is often still edible, and if managed correctly could be given to those who are defined as food-insecure [13]. Although food supply chains in SA have increased dramatically to match our equally fast-growing population, significant numbers of people still suffer from hunger and chronic under/malnourishment. The latest estimates are that one in eight people go hungry or suffer from under/malnourishment [18]. A second major problem associated with large quantities of food waste are alarmingly high greenhouse gas emissions - in particular carbon dioxide and methane [19], [20]. The decomposition of food waste at landfill sites or by incineration contributes to a range of social and environmental problems. It is estimated that the disposal of organic waste contributes approximately $4.3 \%$ of total greenhouse gas emissions in SA [21]. Lastly, food wastage is frustrating not only because of the many natural resources that are wasted, but also because of wasted production costs and economic loss in respect of food that cannot be sold [22].

Key topics such as social responsibility, environmental sustainability, and food security are prominent issues on the agendas of many governments globally. Turning a blind eye to inefficient supply chain and or poor QSR management, which result in food wastage, can no longer be tolerated. SA urgently needs to address the concerns brought about by unnecessary food waste.

\section{METHODOLOGY}

Data collection involved two phases. The first phase was used to collect data from two respective manufacturing plants and 40 QSR stores in Gauteng, SA, through a supply chain audit. It considered practices and managerial protocols along the supply chain that contribute towards waste. Although the focus was on activities that occurred prior to consumption, consumer awareness and behaviour were also noted. Exploratory factor analysis (EFA) of these results allowed the identification of critical areas of concern. Phase 2 involved interviewing QSR managers, and findings collected during this phase allowed the identification of possible mitigating strategies. 


\section{RESULTS}

\subsection{Possible critical areas of concern}

In order to identify critical areas of concern that contribute towards unnecessary food wastage within the QSR industry, field workers had to complete an audit scale which included 70 statements (All scale items were self-designed). In this investigation trained fieldworkers were instructed to respond on each individual scale item by means of a 5 point Likert-type performance scale. Scale labels ranged from $1=$ Extremely concerning to $5=$ Excellent. To summarize and reduce the items in terms of coherent constructs, an EFA, specifically Principal Axis Factoring, was performed. Using an Oblimin rotation with Eigen values $>1.5$ - five factors emerged, which retained 64 of the original scale items. Chronbach's alphas for the factors were $>0.75$. A thorough investigation of the 5 factors and their respective items allowed the identification of suitable factor labels.

Factor 1 Managerial efficiency and general waste awareness at the QSR $(\mathrm{M}=3.69)$

Factor 2 The ability of storage and primary packaging to ensure food product quality and integrity at the QSR $(\mathrm{M}=3.77)$

Factor 3 State of equipment and standard operating procedures at production $(\mathrm{M}=3.72)$

Factor 4 The ability of secondary packaging to protect food product during storage and distribution $(\mathrm{M}=3.53)$

Factor 5 Quality control and standard operating procedures at receiving $(\mathrm{M}=3.98)$

Of the five factors all included the acceptable minimum of at least three scale items. All loadings were also above the acceptable minimum of 0.3 .

Respective factor means revealed that the contents of not only factor $1(\mathrm{M}=3.69)$ (Managerial efficiency and general waste awareness at the QSR) but mostly factor $4(\mathrm{M}=$ 3.53) (Packaging's (Secondary packaging's) ability to protect food product during storage and distribution) could be viewed as possible areas of concern. Calculated means were benchmarked and interpreted in terms of a popular retailing audit rating scale which is currently used in SA retail.

Thus, any mean below 4 was regarded as a possible area of concern and any mean below 3.5 was regarded as a critical area of concern in terms of food wastage.

The fact that packaging (in particular secondary packaging) (Factor 4) was highlighted as the most worrisome area of concern should be viewed as an opportunity in which key supply chain members could make a positive contribution. Scale items in factor 4 reflect not only on the quality of the packaging but more specifically on packaging's ability to protect products during transport / distribution.

Table 1: Current retail audit/rating scale.

\begin{tabular}{|l|l|l|l|}
\hline & Retail rating & Standard & Audit score \\
\hline & Blue status & Excellent & 5.0 \\
\hline & Green status & Good & $4.5-4.9$ \\
\hline & Pass & Fair & $4.0-4.4$ \\
\hline & Red status & Poor & $3.5-3.9$ \\
\hline & Critical failure & Critical area of concern & $<3.5$ \\
\hline
\end{tabular}


Although the respective means for Factors 2 and 3 were slightly better than the means presented by Factors 1 and 4, and therefore do not warrant the same attention, they are also considered as concerning.

In terms of Factor 2 (Storage and packaging's ability to ensure food product quality and integrity) $(\mathrm{M}=3.77)$ it was noted that key supply chain members such as packaging and distribution subsidiaries could once again assist in making a difference. This specific factor emphasises that there is a need for packaging that could minimise food product quality and integrity concerns.

The mean and subsequent contents of Factor $5(\mathrm{M}=3.98)$ (Quality control and standard operating procedures at receiving) were interpreted as the least concerning in terms of its contribution towards food wastage. Findings from the EFA were also supported by the findings presented by the descriptive statistics, which reported that although packaging is identified as an area that warrants further attention, general awareness amongst staff, management and consumers is a serious problem that deserves urgent attention, as this ignorance results in unnecessary wastage throughout the supply chain.

\subsection{Possible mitigating strategies and recommendations}

Results from the interviews held with QSR managers revealed that before food waste can be addressed general awareness amongst all stake holders across the supply chain (i.e. management, staff, as well as consumers) needs to be improved. Findings emphasised the demand for strategic dialogue and knowledge transfer sessions which would not only allow synergy but also collaboration between supply chain members to identify strategies, future policies and initiatives. Topics that must be addressed in these sessions should include a definition of food waste, revision of current protocols, and explaining the future benefits to be gained. Interview findings did however also highlight the need to revise current packaging of bakery products in particular, as the current secondary packaging (e.g. crates) often tend to damage the products during transportation and storage which leads to unnecessary wastage.

\section{CONCLUSIONS}

This study concluded that across the QSR supply chain, food is wasted for many reasons. Results emphasised that mitigation of food waste will require not only practical changes i.e. addressing of production protocols and packaging material, but more importantly an awareness and knowledge component. It is thus of utmost importance to first and foremost address the issue pertaining to management, staff and consumer ignorance before setting out to amend logistical issues. To conclude, one has to assume that nobody would wilfully waste food. However, ending food waste will surely not happen overnight. Simple adjustments such as amending daily habits/ practices and mind-sets should be viewed as a positive start. It would be critical to investigate food wastage further not only to present a holistic picture of the current situation, but to also identify appropriate initiatives that could be implemented to address and mitigate food wastage in future.

\section{REFERENCES}

[1] Rada, E.C., Energy from municipal solid waste. Energy Production and Management in the 21st Century, 2, pp. 945-957, 2014.

[2] Smuts, P.A., Waste characterisation on the African continent - Characterising waste in five cities. Pasco Waste and Environmental Consulting, report compiled for the Bill and Melinda Gates Foundation: Pretoria, South Africa, 2012. 
[3] Gustavsson, J., Cederburg, C., Sonesson, U., Van Otterdijk, R. \& Meybeck, A., Global food losses and food waste: Extent, causes and prevention. Online. www.foa.org/docrep/014/mb060e/mb060e00.pdf. Accessed on: 14 Mar. 2017.

[4] Oelofse, S.H.H. \& Marx-Pienaar, N.J.M.M., Household food wastage: A case study of middle to high income urban households in the city of Tshwane. Wastecon, 1, pp. 51$56,2016$.

[5] Food and Agricultural Organisation (FAO), Food wastage footprint: Impacts on Natural Resources. Summary Report. Food and Agricultural Organisation of the United Nations (FAO), Natural Resources and management Department, Rome, Italy, 2013.

[6] Food and Agricultural Organisation (FAO), Definitional Framework of Food Loss. Working Paper. Save Food and Food Agriculture Organisation of the United Nations, Rome, Italy, 2017.

[7] Aarnio, T. \& Hämäläinen, A., Challenges in packaging waste management in the fast food industry. Resources, Conservation and Recycling, 52(4), pp. 612-621, 2008. DOI: 10.1016/j.resconrec.2007.08.002.

[8] Gustafsson, K., Johnson, G., Smith, D. \& Sparks, L., Retaining Logistics and Fresh Food Packaging: Managing Change in the Supply Chain, Kogan Page Ltd: London, 2006.

[9] Verghese, K., Lewis, H., Lockrey, S. \& Williams, H., Packaging's role in minimizing food loss and waste across the supply chain. Packaging Technology and Science, 28(7), pp. 603-620, 2015. DOI: 10.1002/pts.2127.

[10] Bourlakis, M.A. \& Weightman, P.W.H., Food Supply Chain Management, Blackwell Publishing, 2004.

[11] Holmes, T., SA's Ferocious Fast Food Appetite. Mail and Guardian. Online. https://mg.co.za/article/2016-04-11-sa-has-an-appetite-for-fast-food. Accessed on: 26 Apr. 2017.

[12] Maharaj, Y., Fast food industry report South Africa: Is SA's love for fast food defying banting? Insight Survey B2B Market Research, Cape Town, 2015.

[13] WWF, Food Loss and Waste: Facts and Futures. WWF South Africa. Online. http://awsassets.wwf.org.za/downloads/WWF_Food_Loss_and_Waste_WEB.pdf. Accessed on: 2 Feb. 2018.

[14] Nahman, A. \& De Lange, W., Cost of food waste along the value chain: Evidence from South Africa. Waste Management (NY), 33(11), pp. 2493-5000, 2013.

[15] Derqui, B., Fayos, T. \& Fernandez, V., Towards a more sustainable food supply chain: Opening up invisible waste in food service. Sustainability, 8(693), pp. 1-20 2016.

[16] Waste Resources and Action Programme, Household Food and Drink Waste in the United Kingdom. Online.

www.wrap.org.uk/sites/files/wrap/Household_food_and_drink_waste_in_the_UK_report.pdf. Accessed on: 26 Oct. 2017.

[17] Smil, V., Improving efficiency and reducing waste in our food system. Environmental Sciences, 1(1), pp. 17-26, 2004. DOI: 10.1076/evms.1.1.17.23766.

[18] Keating, B., Food wedges: Framing the global food demand and supply challenges towards 2050. Global Food Security, 3(3-4), pp. 125-132, 2014. DOI: $10.1016 /$ j.gfs.2014.08.004.

[19] Marx-Pienaar, N.J.M.M. \& Erasmus, A.C., Status consciousness and knowledge as potential impediments of households' sustainable consumption practices of fresh produce amidst times of climate change. International Journal of Consumer Studies, 38(4), pp. 419-426, 2014. DOI: 10.1111/ijcs.12111. 
[20] Schiavon, M., Rada, E.C., Ragazzi, M., Cioca, L. \& Torretta, V., Environmental advantages of treatment plants generating biomethane from food waste. Energy and Sustainability, 224, pp. 309-316, 2017.

[21] Oelofse, S.H.H. \& Nahman, A., Estimating the magnitude of food waste generated in South Africa. Waste Management Research, 33(11), pp. 80-86, 2012. DOI: $10.1177 / 0734242 \times 12457117$.

[22] Ferreira, D., Marx-Pienaar, N.J.M.M. \& Sonnenberg, N.C., Postmodern consumers' consciousness of climate change and actions that could mitigate unsustainable consumption. Journal of Family Ecology and Consumer Sciences, Special edition, pp. 13-24, 2016. 